\section{Clinical, pathological and therapeutic findings on lingual rhabdomyosarcoma in a dog - case report}

\author{
[Achados clínicos, patológicos e terapêuticos do rabdomiossarcoma \\ em cão - relato de caso]
}

\begin{abstract}
The biological behaviour of the tumours vary according to the species in which they occur, its location within the cavity, clinical stage and histopathological nature. Lingual neoplasms are generally uncommon in companion animals. Rhabdomyosarcomas are malignant, solid, aggressive formations with high metastatic potential. The clinical signs are variable and a definitive diagnosis can only be reached through histopathological analysis of biopsy and necropsy specimen. In some cases, immunohistochemical study may be needed to confirm the diagnosis. This paper aims to highlight important points about this uncommon condition in dogs, using a case report of lingual rhabdomyosarcoma, which showed no evidence of metastasis after diagnosis, nor of local recurrence after surgical excision with a wide safety margin. It was concluded that early diagnosis, the correct interpretation of the complementary tests and the appropriate therapeutic approach contributed to improving the quality of life and survival of the patient in question.
\end{abstract}

Keywords: tongue, oral neoplasm, small animals

\title{
RESUMO
}

O comportamento biológico dos tumores varia de acordo com a espécie animal, a localização na cavidade, a fase clínica e a natureza histopatológica. As neoplasias orais são geralmente incomuns em animais de companhia. Os rabdomiossarcomas são formações malignas, sólidas e agressivas, com alto potencial metastático. Os sinais clínicos são variáveis e o diagnóstico definitivo só pode ser alcançado por meio da análise histopatológica do material colhido. Em alguns casos, o estudo imuno-histoquímico pode ser necessário para confirmar o diagnóstico. Este trabalho tem como objetivo destacar pontos importantes sobre essa condição incomum em cães, utilizando um relato de caso de rabdomiossarcoma lingual, no qual não se evidenciaram metástases após o diagnóstico, nem recorrência local após a excisão cirúrgica com ampla margem de segurança. Concluiu-se que o diagnóstico precoce, a correta interpretação dos exames complementares e a abordagem terapêutica adequada contribuíram para melhorar a qualidade de vida e a sobrevida do paciente em questão.

Palavras-chave: língua, neoplasia oral, pequenos animais

\section{INTRODUCTION}

Tumours of the tongue are uncommon in small animals, corresponding to only $4 \%$ of all oral and

Recebido em 27 de abril de 2017

Aceito em 25 de janeiro de 2019

*Autor para correspondência (corresponding author)

E-mail: cristiane.honsho@unifran.edu.br pharyngeal neoplasms (Lascelles et al., 1998; Brockus and Myers, 2004; Daleck et al., 2007; Nakaichi et al., 2007) and are often only detected by the owner when already at an advanced stage (Dias et al., 2013). Rhabdomyosarcomas are 
non-odontogenic sarcomas of soft tissues connected to the skeletal musculature (Nakaichi et al., 2007; Kato et al., 2012). They are rare in the oral cavity (Chapman et al., 2008; Murakami et al., 2010; Kimura et al., 2013; Dias et al., 2018) and originate from primitive mesenchymal cells, are malignant, solid, aggressive and have high metastatic potential (Murakami et al., 2010; Kato et al., 2012; Kimura et al., 2013).

The diagnosis of oral tumours is based on the overview, clinical history, symptoms and physical examination of the patient and cytological, histopathological and immunohistochemical analysis (Brockus and Myers, 2004; Chapman et al., 2008). Differential diagnosis must include exuberant connective tissue growth, abscess, encapsulated foreign body, indolent ulcers and ranulas (Daleck et al., 2007). Surgical excision is the treatment of choice for lingual neoplasms with the aim of eliminating the affected tissue while preserving oral function and aesthetics (Dias et al., 2013). Wide surgical excision can lead to $50 \%$ increase in life expectancy in a year (Daleck et al., 2007).

In spite of the age of the animal, the prognosis for patients affected by rhabdomyosarcoma depends on its location on the tongue, time of progression, clinical stage and recurrence (Daleck et al., 2007; Nakaichi et al., 2007). The aim of this paper was to report a rare case of canine lingual rhabdomyosarcoma; to emphasize its clinical characteristics, diagnostic and treatment methods, as well as to stress the importance of periodical inspection of the oral cavity of animals, as early therapeutic intervention can provide better quality of life and greater life expectancy to patients.

\section{CASE REPORT}

The current research was approved on the July $13^{\text {th }} 2013$ by the Ethics Committee in the Use of Animals (protocol number 021/13) from the University of Franca, Brazil. A white, 12 year old female Poodle weighing $4.5 \mathrm{~kg}$ was presented to the Veterinary Hospital of the University of Franca with a nodule on its tongue. The owner reported to have noticed the nodule on the animal's tongue 10 days prior to the examination, with no signs of progressive growth. According to the owner, the animal did not show lingual ptosis, oral bleeding or difficulties in eating dry food or drinking water.

On clinical examination, no significant changes were observed on the animal's general health. On oral cavity examination, a nodule on the frontal third of the lingual border (Figure 1A) was observed, with small ulcerated areas on the dorsal and ventral aspects of the tongue. The nodule was adhered to the musculature (Figure 1B), measured approximately $2 \mathrm{~cm}$ in diameter, was red, painless and firm, and had no areas of necrosis. There were no significant alterations in size, consistency or temperature of the regional lymph nodes and no adhesions or sensitivity. Complementary haematological tests were found to be within the normal range expected for the species. Dorsal-ventral and lateral-lateral views of thoracic X-rays did not suggest of pulmonary metastasis.

Clindamycin $(11 \mathrm{mg} / \mathrm{kg}$ p.o) was given every 12 hours for five days prior to surgery. Biopsy by fine-needle aspiration, carried out under general anesthesia, resulted in malignant neoplasm diagnosis suggestive of carcinoma or sarcoma (the lack neoplastic differentiation occurred due to the nonspecific cellular characteristics that showed marked malignancy). Dental prophylaxis took place and the affected area was excised while respecting safety margins to prevent recurrence. The excised area was removed as a block (Figure 1C) and the blood vessels transfixed. The suture aimed at approximating the remaining borders and great care was taken in reducing the dead space with sultan sutures using poliglactin 910 synthetic absorbable 3-0 diameter surgical thread. After the reduction of the interposed tissue layers, the borders were closed with single interrupted sutures using the surgical thread described above. Samples were collected and sent for histopathological analysis at the Histopathology Laboratory of the same institution.

Although made aware of the risks of suture dehiscence and contamination of the surgical wound, the owner opted for not having an oesophageal tube placed in the animal. Soft food was prescribed for 20 days and the use of a protective collar advised. Post-operative therapy consisted of clindamycin $(11 \mathrm{mg} / \mathrm{kg}$ p.o) given every 12 hours, for ten days; meloxicam $(0.1 \mathrm{mg} / \mathrm{kg}$ p.o) every 24 hours; metamizole 
$(25 \mathrm{mg} / \mathrm{kg}$ p.o $)$ and tramadol $(2 \mathrm{mg} / \mathrm{kg}$ p.o) both given every 8 hours, for five days. Cleaning of the oral cavity was performed with chlorhexidine gluconate $(0.12 \%)$ every 12 hours, for 20 days.

The animal returned five days after surgery showing dehiscence of two sutures; however, there was no need for surgical intervention. The animal had no difficulties in eating or drinking. Significant re-epithelialization of the remainder of the tongue (Figure 1D) was noted by the $20^{\text {th }}$ post-operative day and dry food was reintroduced to the diet.

Histopathological analysis showed the neoplastic mass extended from the sub-epithelial region to the musculature. The mass was round and well defined. Cells varied from fusiform to round, with marked pleomorphic nuclei. Numerous evident nucleoli with poorly defined cytoplasm were observed. Three mitotic figures could be seen in 10 fields of the $400 \times(\mathrm{obj} \mathrm{x} 40)$ (Figure $1 \mathrm{E})$. Immunohistochemistry was performed to obtain a diagnosis due to the lack of cellular differentiation. Positive results for vimentin (clone Vim, final dilution 1:100 Santa Cruz, USA) (Figure 1F) and for slow myosin antibodies (Figure 1G) were observed while no reaction for cytokeratin (clone AE1/AE3, final dilution 1:50, Santacruz, USA) could be seen. Based on the above results, the diagnosis of lingual rhabdomyosarcoma was confirmed.

Periodic returns have demonstrated the absence of neoplastic recurrence and metastases to date, five years after surgery. Even so, the owner became aware of the need for constant checkups.

\section{DISCUSSION AND CONCLUSION}

Tumours of the tongue are uncommon in cats and dogs (Lascelles et al., 1998; Brockus and Myers, 2004; Daleck et al., 2007); which can make it difficult to define some of its parameters such as incidence, aetiology, biological behaviour, breed and sex predisposition, as well as treatment options and prognosis of affected animals (Dias et al., 2013).
Although rare in the oral cavity (Lascelles et al., 1998; Chapman et al., 2008; Murakami et al., 2010; Gandi and Vivekanand, 2012; Kimura et al., 2013), rhabdomyosarcomas are more commonly reported in dogs than in cats, horses or cattle (Chapman et al., 2008). Moreover, they are recurrent, metastatic and their behaviour and the survival of patients after removal are poorly documented in animals (Lascelles et al., 1998; Nakaichi et al., 2007). Within this context, Lascelles et al. (1998) reported the first case of lingual rhabdomyosarcoma, which was diagnosed in a 6 year-old dog that presented recurrence following surgical removal, radiotherapy and chemotherapy treatments. In 2004, Brockus and Myers observed rhabdomyosarcoma on the caudal region of the tongue of a 10 year-old crossbreed female dog, with signs of metastasis and recurrence 10 months after surgical excision. Kimura et al. (2013) reported a case affecting the gums of a young $\operatorname{dog}$ (3 years old), which had to be euthanized due to the rapid and invasive growth of the mass towards the orbit, even after one month of cryotherapy. Gandi and Vivekanand (2012) reported two cases in young dogs, a jaw and a gum tumor causing metastases in regional lymph nodes and lungs. The animals died two months after diagnosis, even though they'd undergone surgical removal and chemotherapy, contrary to observed in this case, where the patient remains healthy after five years of isolated surgical excision, emphasizing the importance of early diagnosis and treatment, as described by Daleck et al. (2007) and Nakaichi et al. (2007).

The breed of the reported patient is in agreement with the findings of Daleck et al. (2007); however, the sex contradicts other findings. Even though oral neoplasms affect mostly middle-aged and older animals, Murakami et al. (2010) have reported a case of maxillary rhabdomyosarcoma on a 15 month-old dog. The animals affected with oral neoplasms can present with severe halitosis, ptyalism, blood streaked saliva, poor dental occlusion, scratching of the mouth, difficulty in seizing food, hyporexia, dyspnea, weight loss and difficulty in drinking (Daleck et al., 2007). Nevertheless, the animal in the present report was asymptomatic. 


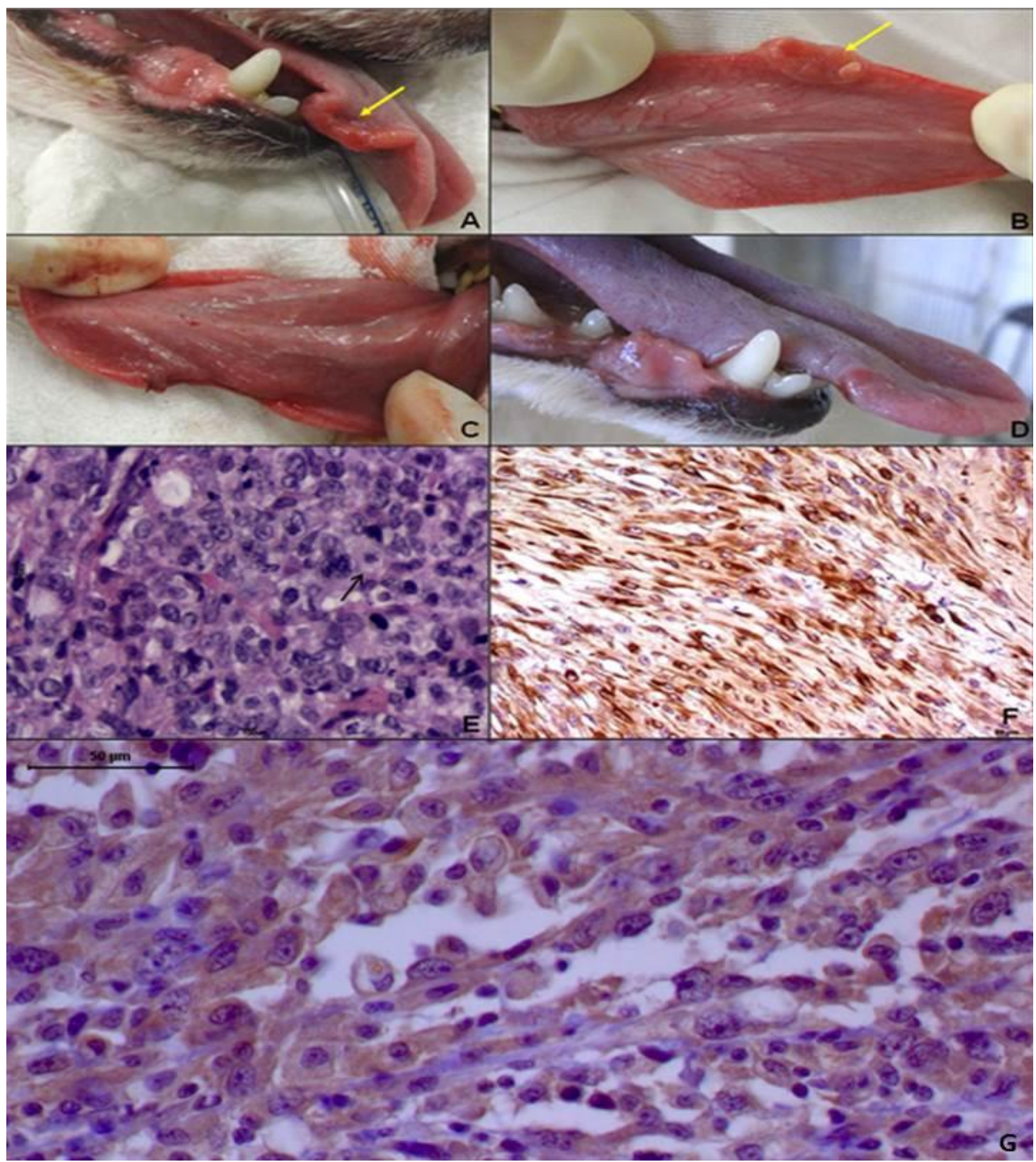

Figure 1. Photography and photomicrographic images of the reported dog: A. Photography of the oral cavity of a dog with a nodule on the frontal third of the right lingual border with areas of ulceration (arrow); B. Photography of the tongue of a dog with a nodule in the musculature (arrow); C. Photography of the ventral aspect of the tongue of a dog after partial right glossectomy following nodule excision; D. Photography showing re-epithelialization of the remaining lingual tissue 20 days after partial right glossectomy; E. Photomicrography of rhabdomyosarcoma of the tongue in a dog. Hematoxylin and eosin, Obj $\times 40$. Accentuated nuclear pleomorphysm, evident nuclei and poorly defined cytoplasm. Mitotic figures can be seen (arrow); F. Photomicrography of tumour biopsy subjected to immunohistochemistry using system reveal, Obj x 20. Brown colouring indicate positive reaction to vimentin, biotin-free system. Note intense vimentin marking by the tumour, confirming mesenchymal origin; G. Photomicrography of rhabdomyosarcoma of the tongue in a dog. Immunostaining for slow myosin, biotin-free system, reveal, Obj x 40. Note staining cytoplasmic, focally positive. 
Although fine-needle aspiration cytology is a quick, inexpensive and minimally invasive technique (Murakami et al., 2010), it is not always reliable as the quantity of specimen collected may be insufficient for analysis and diagnosis; therefore, histopathology is usually indispensable (Brockus and Myers, 2004; Chapman et al., 2008). The histopathological findings of the present case were similar to those found by Dias et al. (2018) in a dog with laringeal rhabdomyosarcoma. In the current study, immunohistochemistry was performed to identify proteins in order to confirm the origin of the neoplasm since the lack of differentiation of the tumour could cast doubt on the diagnosis. A positive reaction could be observed for vimentin (clarifying the diagnosis of sarcoma) as described by Lascelles et al. (1998), Brockus and Myers (2004), Chapman et al. (2008), Murakami et al. (2010) and Kimura et al. (2013) while no reaction was observed for cytokeratin (excluding the possibility of carcinoma) as described by Lascelles et al. (1998), Kato et al. (2012) and Kimura et al. (2013). Regarding the markers, the protein myosin, present in muscle contractions, characterized a skeletal muscle neoplasm that is the muscular type of the tongue. Despite the importance of immunohistochemistry in the investigation of neoplasms of the stomatognathic system, there are descriptions of the diagnosis of rhabdomyosarcoma in maxilla of three dogs (Nakaichi et al., 2007) and larynx of a dog (Dias et al., 2018) only by histopathological examination.

Surgical excision was the treatment of choice as dogs are quite tolerant to partial glossectomy (Nakaichi et al., 2007). The neoplasm nodule was relatively small and there were no signs of metastasis. Furthermore, the same authors point out that currently no effective chemotherapy protocol is available for tumours found in this region. Lascelles et al. (1998) have also reported the inefficacy of chemotherapy (Vincristine, Cyclophosphamide and Prednisolone) administered for five weeks, even when in conjunction with surgical excision and radiotherapy. Thus, Nakaichi et al. (2007) did not achieve good results when three dogs with oral rhabdomyosarcoma were treated with a combination of surgical excision and radiotherapy, as there was recurrence and pulmonary metastasis leading to the animals' death two months after admission.

In the reported case, the cranial location of the neoplasm was a positive factor in the prognosis as it enabled early detection by the owner, who sought veterinary assistance promptly. It also allowed for surgical excision with good safety margins, unlike the case described by Lascelles et al. (1998), in which two surgical interventions on a rhabdomyosarcoma located on the dorsal region of the tongue and of a significant size to the organ in question resulted in no clinical improvement of the patient. Another point to be considered on the prognosis in the present study is the low number of blood and lymph vessels present in this region of the tongue, which may have contributed to the absence of metastasis (Daleck et al., 2007), contrary to that observed in the case reported by Brockus and Myers (2004).

The suture dehiscence, a common occurrence in the lingual region (Dias et al., 2013), most likely happened due to local friction by the right upper teeth and contamination of the oral cavity. Even though many authors have described rhabdomyosarcomas as aggressive and with high metastatic potential (Murakami et al., 2010; Kimura et al., 2013), no metastasis or recurrence was observed in the reported animal up to five years after detection and surgical excision, overcoming life expectancy cited by Daleck et al. (2007). As the majority of owners do not have the habit of regularly checking the oral cavity of their animals, conditions affecting this region often go undetected. However, in this case, the early diagnosis, the location of the tumour and the regular check ups were factors of uttermost importance in ensuring the significant diseasefree survival time. This is the first case of a dog with lingual rhabdomyosarcoma that has survived for over five years and that has shown no signs of recurrence or metastasis after a single surgical intervention.

The wide surgical excision, although aggressive, ensured the resolution of the case for the time being, with no interference on feeding habit or oral discomfort in spite of the malignancy of the neoplasm. 


\section{REFERENCES}

BROCKUS, C.W.; MYERS, R.K. Multifocal rhabdomyosarcomas within the tongue and oral cavity of a dog. Vet. Pathol., v.41, p.273-274, 2004.

CHAPMAN, S.; NABITY, M.; CALISE, D. What is your diagnosis? Lingual mass in a dog. Vet. Clin. Pathol., v.37, p.133-139, 2008.

DALECK, C.R.; NARDI, A.B.; SILVA, M.C.V.; et al., Neoplasias de língua em cinco cães. Cienc. Rural, v.37, p.578-582, 2007.

DIAS, F.G.G.; CINTRA, P.P.; CALAZANS, S.G.; et al. Laryngeal rhabdomyosarcoma in a dog: case report. Arq. Bras. Med. Vet. Zootec., v.70, p.1423-1426, 2018.

DIAS，F.G.G.; DIAS， L.G.G.G.; PEREIRA, L.F.; et al.,. Neoplasias orais nos animais de companhia - revisão de literatura. Rev. Cient. Eletron. Med. Vet., v.11, p.1-9, 2013.

GANDI, L.; VIVEKANAND, S. Maxillofacial rhabdomyosarcoma in the canine maxillofacial area. Vet. World, v.5, p.565-567, 2012.
KATO, Y.; NOTAKE, H.; KIMURA, J. et al. Orbital embryonal rhabdomyosarcoma with metastasis in a young dog. J. Comp. Pathol., v.47, p.191-194, 2012.

KIMURA, M.; SUZUKI, K.; FUJI, Y. et al. Gingival rhabdomyosarcoma accompanied by an immature myogenic population immunoreactive for $\alpha$-smooth muscle actin in a dog. J. Comp. Pathol., v.149, p.48-52, 2013.

LASCELLES, B.D.; MCLANNES, E.; DOBSON, J.M.; WHITE, R.A. Rhabdomyosarcoma of the tongue in a dog. $J$. Small Anim. Pract, v.39, p.587-591, 1998.

MURAKAMI, M.; SAKAI, H.; IWATANI, N. et al. Cytologic, histologic and immunohistochemical features of maxillofacial alveolar rhabdomyosarcoma in a juvenile dog. Vet. Clin. Pathol., v.39, p.113-118, 2010.

NAKAICHI, M.; ITAMOTO, K.; HASEGAWA, K. et al. Maxillofacial rhabdomyosarcoma in the canine maxillofacial area. J. Vet. Med. Sci., v.69, p.65-67, 2007. 